\title{
Media Pembelajaran Berbantuan Komputer untuk Meningkatkan Prestasi Siswa Kelas XII SMA pada Materi Kaidah Pencacahan
}

\author{
Pujianto $^{1}$, Swasono Rahardjo ${ }^{1}$ \\ ${ }^{1}$ Pendidikan Matematika-Universitas Negeri Malang
}

\begin{tabular}{l}
\hline \hline INFO ARTIKEL \\
\hline Riwayat Artikel: \\
Diterima: 07-01-2019 \\
Disetujui: 18-02-2019 \\
\hline
\end{tabular}

Kata kunci:

computer;

mathematics;

enumeration rules;

komputer:

matematika;

kaidah pencacahan

\begin{abstract}
ABSTRAK
Abstract: The purpose of developing this computer-assisted learning media is to improve student learning achievement in rules for high school class XII students. The research development model uses the Plomp model divided into five stages, namely (1) initial investigation, (2) design, (3) making, (4) trial and revision, and (5) application. This media is called Bel Kaca. The results of this study are computer-assisted learning media that are valid, effective, and practical for use in teaching and learning activities.

Abstrak: Tujuan dari pengembangan media pembelajaran berbantuan komputer ini adalah untuk meningkatkan prestasi belajar siswa pada materi kaidah pencacahan untuk siswa kelas XII SMA. Model pengembangan penelitian ini menggunakan model Plomp terbagi lima tahapan yaitu (1) penyelidikan awal, (2) rancangan, (3) pembuatan, (4) ujicoba dan revisi, dan (5) penerapan dan penyebaran. Media ini bernama Bel Kaca. Hasil dari penelitian ini adalah media pembelajaran berbantuan komputer ini valid, efektif, dan praktis untuk digunakan dalam kegiatan belajar mengajar.
\end{abstract}

\section{Alamat Korespondensi:}

\section{Pujianto}

Pendidikan Matematika

Universitas Negeri Malang

Jalan Semarang 5 Malang

E-mail: pujiantomuhammad@yahoo.com

Teknologi dan ilmu pengetahuan banyak membawa perubahan di berbagai bidang baik pendidikan, budaya, sosial, dan agama. Oleh sebab itu, supaya pendidikan tidak tertinggal perlu penyesuaian-penyesuaian dengan teknologi (Sucahyono, 2016). Salah satu teknologi yang berkembang pesat saat ini adalah komputer. Komputer adalah teknologi pembaharuan yang berkembang sangat pesat (Yusuf, Kamdi, Patmanthara, 2016). Maka dari itu perlu penggunaan media komputer dalam pengajaran atau proses belajar mengajar di kelas. Dengan berkembangnya teknologi dalam pembelajaran di kelas, setiap siswa seharusnya minat dan tertarik dengan mata pelajaran matematika. Akan tetapi, kenyataannya berdasarkan survei pendahuluan peneliti di beberapa sekolah di kota Kediri minat belajar siswa sebagian besar masih rendah. Sebagian dari mereka menganggap bahwa matematika termasuk mata pelajaran yang susah dan membosankan. Hal ini sesuai dengan pendapat Istiqlal yang menyatakan bahwa matematika merupakan pelajaran yang dikategorikan sulit (Istiqlal \& Wutsqa, 2013).

Peneliti menganggap hal ini ada beberapa penyebab yaitu media yang digunakan oleh pendidik masih kurang begitu efektif serta proses pembelajaran yang dilakukan oleh pendidik masih monoton didominasi oleh guru, sedangkan siswa di kelas hanya duduk, mendengarkan, mencatat dan mengerjakan tugas-tugas dari guru. Rusman berpendapat bahwa guru sebaiknya tidak sekedar berpengetahuan terkait media pembelajaran saja, tetapi guru harus mempunyai keterampilan membuat atau mengembangkan media pembelajaran dengan bagus (Rusman, 2013).

Penggunaan komputer dalam dunia pendidikan sangat penting sekali untuk meningkatkan minat dan prestasi belajar siswa (Surya, 2015). Untuk meningkatkan minat belajar siswa perlu media pembelajaran yang efektif dan menarik sehingga dapat memberikan dampak positif bagi siswa (Silviani, Jailani, Lusyana, \& Rukmana, 2017). Media pembelajaran yang penulis kembangkan adalah media belajar dengan berbantuan komputer yang dapat dipergunakan peserta didik secara mandiri di rumah dan siswa dapat mengulang-ulang materi yang belum mereka pahami. Media pembelajaran ini juga dapat sebagai tutor dalam pembelajaran di rumah secara mandiri karena media ini memberikan konten secara menarik dan umpan balik kepada siswa dengan cepat. Dalam buku NCTM disebutkan bahwa teknologi sangat penting dalam menunjang proses pembelajaran di dalam kelas dan teknologi juga berpengaruh dalam proses belajar peserta didik (NCTM, 2000). Dalam pengembangan media peneliti menggunakan Adobe CS 6 karena menurut Fatimah menyatakan bahwa Adobe Flash CS 6 mempunyai beberapa kelebihan jika dibandingkan dengan aplikasi lain yang sejenis dengannya (Fatimah, 2016). 
Dalam mengembangkan multimedia berbantuan komputer yang baik diperlukan analisis yang teliti agar tidak terjadi kesalahan pada media (Ariawan \& Muhsetyo, 2017). Materi yang disajikan pun harus ditampilkan secara menarik sehingga siswa atau peserta didik tidak merasa jenuh dalam belajar matematika. Dengan latar belakang tersebut peneliti mengembangkan media pembelajaran dengan bantuan komputer untuk meningkatkan prestasi belajar siswa kelas XII SMA pada materi kaidah pencacahan.

\section{METODE}

Penelitian pengembangan ini menggunakan model Plomp (Plomp, 2006). Plomp memberikan suatu model dalam mendesain model pengembangan yang terbagi menjadi lima tahapan. yaitu 1) penyelidikan awal, (2) rancangan, (3) pembuatan, (4) tahap ujicoba dan revisi, dan (5) penerapan dan penyebaran. (Tjiptiany \& Muksar, 2016). Pada tahapan penyelidikan awal peneliti melakukan pengumpulan data awal, analisis permasalahan di sekolah, dan analisis kebutuhan media bagi siswa dan guru matematika. Selanjutnya, pada tahapan rancangan kegiatan yang dilakukan adalah menentukan Kompentensi Dasar dan indikator pencapaian kompetensi yang akan dikembangkan pada media kemudian mendesain bentuk media. Tahapan ketiga adalah pembuatan media. Peneliti dalam pembuatan media berbantuan komputer ini menggunakan Adobe CS6 yang memiliki fitur yang cukup. Tahapan keempat adalah ujicoba atau tes untuk mengetahui apakah media yang dikembangkan valid, praktis dan efektif. Tahapan yang terakhir adalah diseminasi atau penyebaran. Pada tahapan ini setelah media dikatakan valid, praktis dan efektif selanjutnya media disebarkan di beberapa sekolah untuk diimplementasikan dalam proses belajar mengajar di sekolah.

Dalam penelitian pengembangan media pembelajaran berbantuan komputer ini menggunakan subjek 22 siswa kelas XIIB di SMA Ar Risalah Kota Kediri. Sebelum melakukan penelitian peneliti menyusun indikator kevalidan dan keefektifan untuk diajukan kepada validator yaitu seseorang yang bergelar doktor program studi pendidikan matematika dan berpengalaman pada bidangnya. Fungsi dari validasi adalah untuk menguji media yang dikembangkan valid atau tidak. Jika tidak maka akan ada revisi sehingga sampai media benar-benar valid. Indikator kepraktisan diujicobakan kepada guru kelas XII SMA Ar Risalah dan 22 siswa kelas XII SMA Ar Risalah Kota Kediri. Uji kepraktisan ini terdiri dari 22 indikator untuk guru dan 25 indikator untuk siswa. Untuk mengetahui tingkat keefektifan media peneliti menyusun 10 soal terkait dengan kaidah pencacahan. Soal tersebut diberikan kepada 22 siswa. Teknik penskoran kevalidan, kepraktisan, dan keefektifan dengan menggunakan rumus dan kriteria sebagai berikut. Untuk menghitung skor kevalidan $\left(V_{a}\right)$ menggunakan dengan rumus (Khusna, Yuwono, \& Muksar, 2016).

$$
V_{a}=\frac{\sum_{i=1}^{n} I_{i}}{m}
$$

Dengan $\sum_{i=1}^{n} I_{i}$ adalah jumlah hasil validasi pada indikator ke-i dan m adalah banyaknya indikator. Kriteria kevalidan produk mengacu pada tabel 1 (Safrida, Asari, \& Sisworo, 2016). Kedua untuk mengetahui tingkat kepraktisan peneliti menyusun indikator kepraktisan, kemudian di indikator tersebut divalidasi oleh validator. Indikator kepraktisan tersebut diberikan kepada guru dan siswa dan tingkat kepraktisan dihitung menggunakan rumus berikut (Hobri, 2010). Dengan $\sum_{i=1}^{n} I_{i}$ adalah jumlah nilai hasil uji kepraktisan pada indikator ke- $i$ dan $\mathrm{n}$ adalah banyaknya indikator. Kriteria kepraktisan mengacu pada tabel 2 .

$$
P_{r}=\frac{\sum_{i=1}^{n} I_{i}}{n}
$$

Tabel 1. Kriteria Kevalidan Produk

\begin{tabular}{ll}
\hline Skor Kevalidan & Kategori \\
\hline $3 \leq \mathrm{V} \leq 4$ & Valid \\
$2 \leq \mathrm{V}<3$ & Cukup Valid \\
$1 \leq \mathrm{V}<2$ & Tidak Valid \\
\hline
\end{tabular}

Tabel 2. Kriteria Kepraktisan Produk

\begin{tabular}{ll}
\hline \multicolumn{1}{c}{ Nilai } & \multicolumn{1}{c}{ Kategori } \\
\hline $\mathrm{P}=4$ & Sangat Praktis \\
$3,25 \leq \operatorname{Pr}<4$ & Praktis \\
$2,50 \leq \operatorname{Pr}<3,25$ & Cukup Praktis \\
$1,75 \leq \operatorname{Pr}<2,50$ & Kurang Praktis \\
$1,00 \leq \operatorname{Pr}<1,75$ & Tidak Praktis \\
\hline
\end{tabular}


Untuk mengetahui tingkat keefektifan peneliti menyusun 10 soal yang akan diujikan kepada siswa. Soal tersebut diberikan kepada siswa dan hasil penilaian dihitung menggunakan rumus berikut (Widiyoko, 2010). Kriteria keefektifan mengacu pada tabel 3 (Jhonson \& Tambunan, 2014).

$$
E f=\frac{x}{n} \times 100 \%
$$

\section{Keterangan:}

E: persentase peserta didik yang pendapat skor di atas SKM

$\mathrm{x}$ : banyaknya peserta didik yang pendapat skor di atas SKM

$\mathrm{n}$ : banyaknya peserta didik dalam uji coba

Tabel 3. Kriteria Keefektifan Produk

\begin{tabular}{ll}
\hline Persentase siswa yang tuntas belajar & Kategori \\
\hline $80 \% \leq \mathrm{Ef} \leq 100 \%$ & Sangat Baik \\
$60 \% \leq \mathrm{Ef}<80 \%$ & Baik \\
$40 \% \leq \mathrm{Ef}<60 \%$ & Cukup Baik \\
$20 \% \leq \mathrm{Ef}<40 \%$ & Kurang Baik \\
$0 \% \leq \mathrm{Ef}<20 \%$ & Tidak Baik \\
\hline
\end{tabular}

\section{HASIL DAN PEMBAHASAN}

Hasil dari penelitian ini merupakan sebuah aplikasi berekstensi exe yang digunakan pada kelas XII SMA pada materi kaidah pencacahan. Media pembelajaran berbantuan komputer ini dikemas secara interaktif yang membuat siswa senang dan tertarik serta termotivasi untuk belajar.

Untuk mengetahui keefektifan, media ini diujicobakan pada 22 siswa SMA Ar Risalah Kota Kediri. Untuk mengetahui tingkat kepraktisan, peneliti memberikan angket pada seorang guru dan 22 siswa SMA Ar Risalah Kota Kediri. Hasil setiap indikator dianalisis dan hasil dari media pembelajaran berbantuan komputer ini katakan layak (valid) dengan skor ahli media 3,08; ahli materi 3,05; hasil keefektifan media 85,59\% dengan 90\% siswa di atas KKM dan hasil kepraktisan media 3,6; Gambar 1-3 merupakan hasil dari penilaian ahli media, ahli materi, dan pensekoran kepraktisan oleh guru mata pelajaran matematika.

Berdasarkan hasil validasi ahli materi didapatkan nilai 3,05; Hal ini artinya media pembelajaran berbantuan komputer ini layak untuk digunakan pada pembelajaran di kelas. Berdasarkan hasil validasi yang telah dilakukan terhadap ahli media didapatkan nilai 3,08; hal ini artinya media dikatakan valid atau layak untuk dimanfaatkan dalam proses belajar mengajar di kelas. Hasil validasi dari ahli materi dan ahli media maka produk dikatakan valid dengan tingkat kevalidan 3,07. Hasil dari angket guru dan siswa terhadap kepraktisan produk sebesar 3,6 hal ini artinya media pembelajaran yang di kembangkan dapat diinterpretasikan mudah untuk digunakan pada proses pembelajaran.

Berdasarkan hasil tes evaluasi tingkat pemahaman siswa terhadap materi kaidah pencacahan diperoleh jumlah persentase 85,59\% dengan 90\% siswa di atas Kriteria Ketuntasan Minimum maka dapat dikatakan bahwa media pembelajaran berbantuan komputer yang dikembangkan termasuk dalam kategori efektif dan layak untuk manfaatkan dalam proses belajar mengajar di kelas. Dengan demikian, dapat dijelaskan menurut kriteria yang telah ditentukan hasil belajar siswa dapat diinterpretasikan bahwa media pembelajaran berbantuan komputer dapat dikatakan valid, praktis, dan efektif untuk dimanfaatkan dalam proses belajar mengajar di kelas.

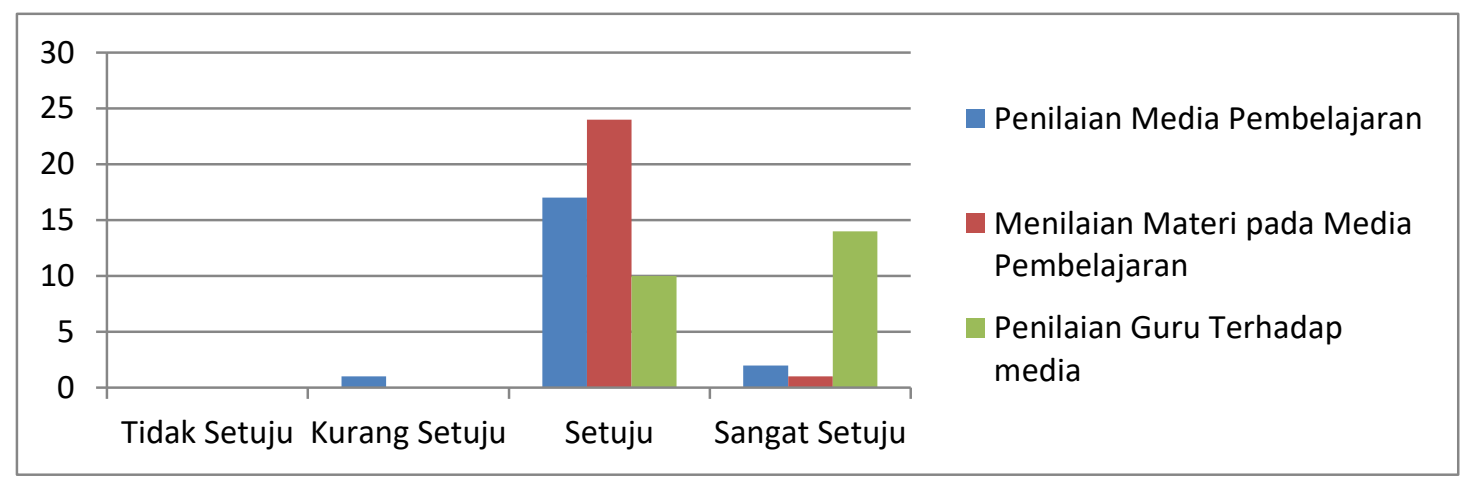

Gambar 1. Penilaian Ahli Media, Ahli Materi, dan Guru terhadap Media Pembelajaran 


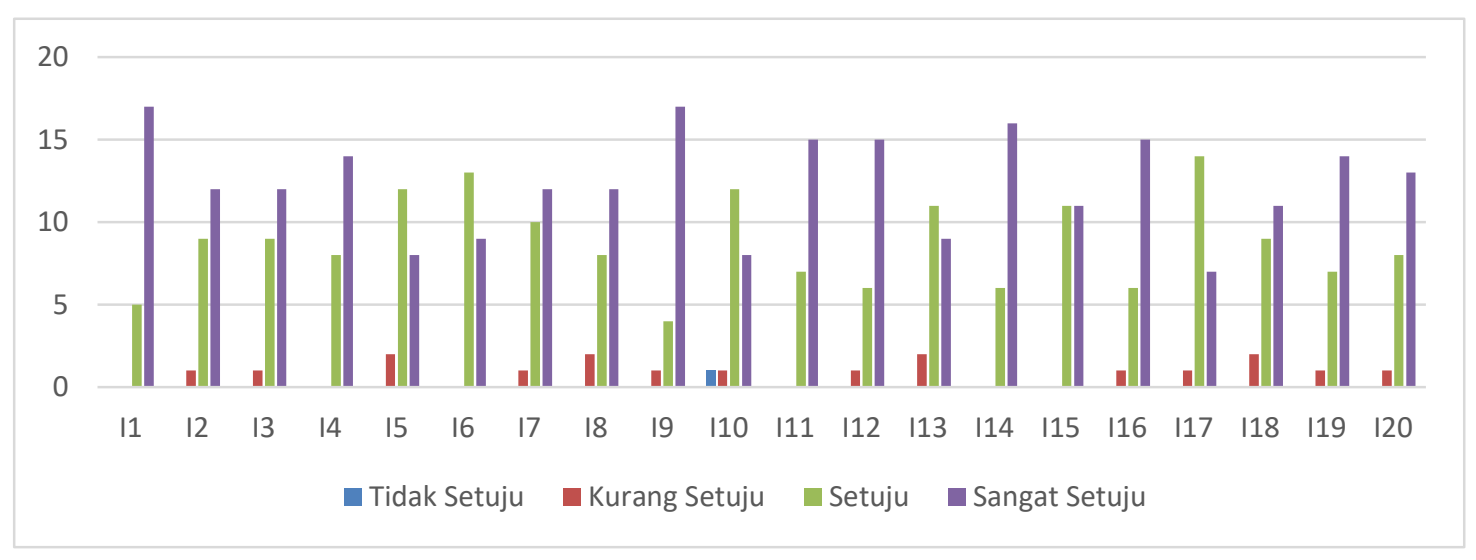

Gambar 2. Hasil Penilaian Siswa terhadap Media Pembelajaran

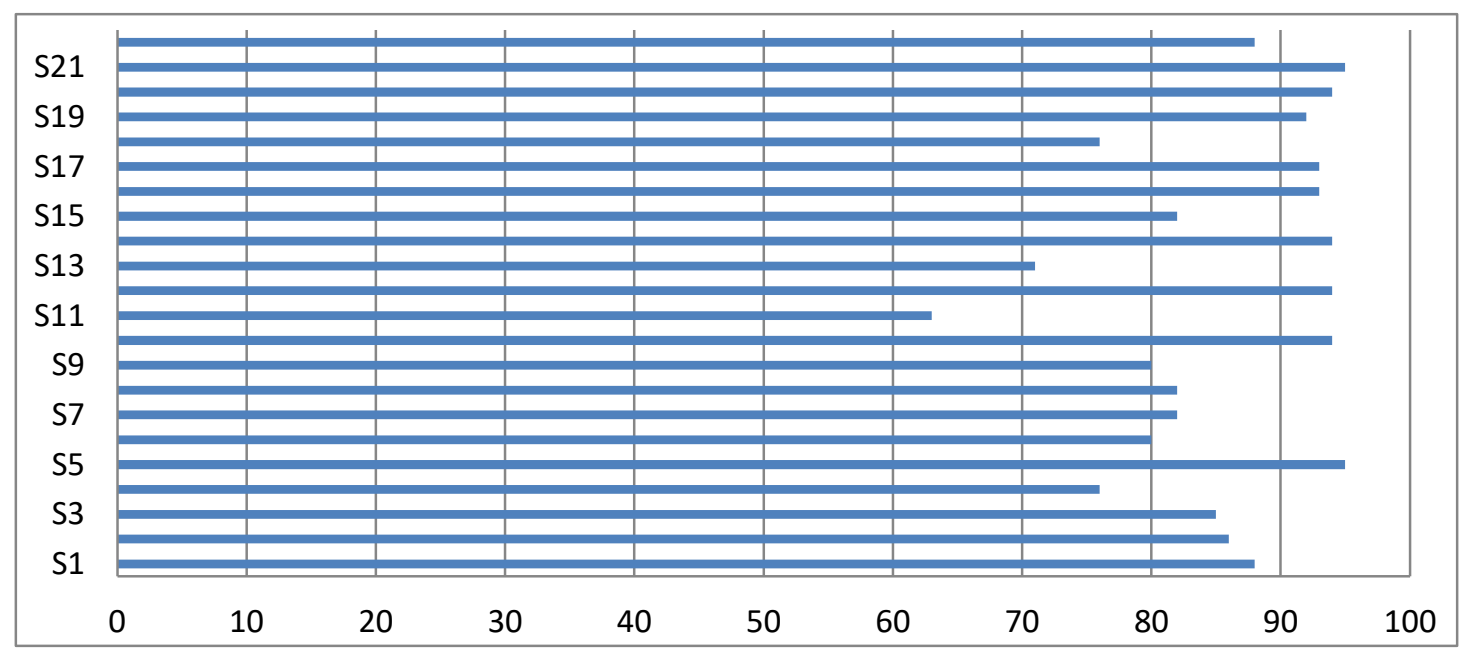

Gambar 3. Hasil Uji Keefektifan Media Pembelajaran

SIMPULAN

Pengembangan media pembelajaran berbantuan komputer ini dirancang mengikuti model pengembangan Plomp (Plomp 2006). Dengan spesifikasi produk berupa media pembelajaran berbantuan komputer pada materi kaidah pencacahan. Hasil dari penelitian dan pengembangan media pembelajaran berbantuan komputer ini dapat digunakan pada proses belajar mengajar di kelas. Media pembelajaran berbantuan komputer ini dibuat dalam bentuk aplikasi flash yang mudah digunakan pada media komputer atau laptop. Media ini dilengkapi dengan materi kaidah pencacahan, contoh soal, latihan dan soal evaluasi. Pada media ini terdapat konten yang di sesuaikan dengan tingkat kemampuan siswa kelas XII SMA.

Media pembelajaran berbantuan komputer ini telah divalidasi oleh seorang ahli media dan ahli materi yakni dosen pascasarjana program pendidikan matematika dan guru mata pelajaran Matematika SMA Ar Risalah Kota Kediri yang menyatakan bahwa media pembelajaran berbantuan komputer ini layak untuk dipergunakan pada proses belajar mengajar pada mata pelajaran matematika XII di SMA pada materi kaidah pencacahan. Pengembangan media pembelajaran berbantuan komputer ini disempurnakan melalui proses revisi, yaitu mengurangi beberapa tampilan yang tidak perlu dan menambah tampilan yang diperlukan.

Berdasarkan penelitian pengembangan, agar mendapatkan manfaat yang optimal terhadap produk ataupun kajian dalam penelitian ini, maka memberikan saran bahwa siswa yang menggunakan produk harus sudah memahami materi prasyarat yaitu materi perkalian bilangan bulat dan produk juga dapat digunakan oleh siswa SMK karena merupakan materi matematika wajib yang juga diajarkan di SMK dan perlu dikembangkan media pembelajaran matematika yang mirip dengan produk dengan materi yang berbeda. 


\section{DAFTAR RUJUKAN}

Ariawan, B., Muhsetyo, G., \& Qohar, A. (2017). Pengembangan Edutainment Multimedia Belajar Program Linier Siswa SMK. Jurnal Pendidikan: Teori, Penelitian, dan Pengembangan, 2(6), 780-789.

Fatimah. (2016). Pengembangan Media Pembelajaran Menggunakan Software Adobe Flash Professional Cs6 pada Materi Gula dan Hasil Olahnya untuk Siswa Kelas X Jasa Boga SMK Negeri 1 Sewon. Tesis tidak diterbitkan. Universitas Negeri Yogyakarta, Yogyakarta.

Hobri. (2010). Metodologi Penelitian Pengembangan dan Aplikasi pada Penelitian Pendidikan Matematika. Jakarta: Rineka Cipta.

Istiqlal, M., \& Wutsqa, D. U. (2013). Pengembangan Multimedia Pembelajaran Matematika SMA untuk Meningkatkan Motivasi dan Prestasi Belajar Matematika Materi Logika. Pythagoras: Jurnal Pendidikan Matematika, 8(1), 44-54.

Jhonson., \& Tambunan, H. (2014). Pengembangan Media Pembelajaran Interaktif Berbasis Visual Basic dan Smoothboard pada Matematika. Jurnal Teknologi Informasi dan Komunikasi Dalam Pendidikan, 1(1), 98-109.

Khusna, A. H., Yuwono, I., \& Muksar, M. (2016). Pengembangan Lembar Kerja Siswa (LKS) Berkarakteristik RME Materi Barisan dan Deret untuk Kelas X. Jurnal Pendidikan: Teori, Penelitian, dan Pengembangan, 1(4), 739-745.

NCTM. (2000). Principles and Standards for School Mathematics. United States: The National Council of Teacher of Mathematics.

Plomp, T. (2006). Teaching and Learning for the Future. Committee on Multimedia in Teacher Training, Final Report.

Rusman. (2013). Belajar dan Pembelajaran Berbasis Komputer-Mengembangkan Profesinalisme Pendidik Abad 21. Bandung: Alfabeta.

Safrida, L. N., Asari, A. R., \& Sisworo. (2016). Pengembangan Perangkat Pembelajaran Berbasis Problem Solving Polya untuk Meningkatkan Kemampuan Penalaran Matematis Siswa Materi Peluang Kelas XI SMA. Jurnal Pendidikan: Teori, Penelitian, dan Pengembangan, 1(4), 583-591.

Silviani, T. R., Jailani., Lusyana, E., \& Rukmana, A. (2017). Upaya Meningkatkan Minat Belajar Matematika menggunakan Inquiry Based Learning Setting Group Investigation. Kreano: Jurnal Matematika Kreatif-Inovatif, 8(2), 150-161. DOI: https://doi.org/10.15294/kreano.v8i2.8404

Sucahyono, B. (2016). Analisa Efesiensi Penerapan Media Ajar Berbasis Digital Class pada SMPN 4 Pamekasan. Insand Comtech: Information Science and Computer Technology Journal, 1(1), 27-31.

Surya, E. (2015). Pengembangan Model Pembelajaran Matematika SMP Berbasis Budaya Daerah Melayu Sumatera Utara Jurnal Inspiratif, 1(1), 83-95.

Tjiptiany, E. N., \& Muksar, M. (2016). Pengembangan Modul Pembelajaran untuk Membantu Siswa SMA Kelas X dalam Memahami Materi Peluang. Jurnal Pendidikan: Teori, Penelitian, dan Pengembangan, 1(10), 1938-1942.

Widiyoko, S. (2010). Evaluasi Program Bembelajaran Panduan Praktis bagi Pendidik. Yogyakarta: Pustaka Belajar.

Yusuf, F. E., Kamdi, W., \& Patmanthara, S. (2016). Pengembangan Multimedia Interaktif pada Mata Pelajaran Produktif TKJ di SMK Widyagama Malang. Jurnal Pendidikan: Teori, Penelitian, dan Pengembangan, 1(4), 650-654. 